\title{
A randomized, controlled, crossover trial to assess the acute appetitive and metabolic effects of sausage and egg-based convenience breakfast meals in overweight premenopausal women
}

Tia M Rains ${ }^{1,3^{*}}$, Heather J Leidy ${ }^{2}$, Kristen D Sanoshy ${ }^{3}$, Andrea L Lawless ${ }^{3}$ and Kevin C Maki ${ }^{3,4}$

\begin{abstract}
Background: Dietary protein at breakfast has been shown to enhance satiety and reduce subsequent energy intake more so than carbohydrate or fat. However, relatively few studies have assessed substitution of protein for carbohydrate on indicators of appetite and glucose homeostasis simultaneously.

Methods: The acute appetitive and metabolic effects of commercially-prepared sausage and egg-based breakfast meals at two different protein levels (30 g and $39 \mathrm{~g} /$ serving), vs. a low-protein pancake breakfast ( $3 \mathrm{~g}$ protein) and no breakfast (water), were examined in premenopausal women ( $N=35$; age $32.5 \pm 1.6 \mathrm{yr}$; BMl $\left.24.8 \pm 0.5 \mathrm{~kg} / \mathrm{m}^{2}\right)$. Test products provided $\sim 280 \mathrm{kcal} / \mathrm{serving}$ and similar fat $(12-14 \mathrm{~g})$ and fiber contents $(0-1 \mathrm{~g})$. Visual Analog Scale ratings for appetite (hunger, fullness, prospective consumption, desire to eat) and repeated blood sampling for plasma glucose and insulin concentrations were assessed throughout each test day. Energy intake was recorded at an ad libitum lunch meal at 240 min.

Results: Results showed increased satiety ratings for both the 30 and $39 \mathrm{~g}$ protein meals vs. the low-protein and no breakfast conditions ( $p<0.001$ for all). Postprandial glucose and insulin excursions were lower following the $30 \mathrm{~g}$ and $39 \mathrm{~g}$ protein conditions vs. the low-protein condition, with smaller responses following the $39 \mathrm{~g}$ vs. $30 \mathrm{~g}$ protein condition $(p<0.05$ for all). Energy intake at lunch was significantly less $(p<0.001)$ following the $39 \mathrm{~g}$ protein meal $(692 \mathrm{kcal}) \mathrm{vs}$. the low-protein and no breakfast conditions (789 and $810 \mathrm{kcal}$, respectively). Total energy intake from the test condition + lunch was higher $(p<0.01)$ for the 30 and $39 \mathrm{~g}$ meals (982 and $983 \mathrm{kcal}$, respectively) vs. no breakfast $(810 \mathrm{kcal})$, and less than the low protein breakfast (1064 kcal; $p<0.01 \mathrm{vs.} 39 \mathrm{~g}$ condition only).
\end{abstract}

Conclusions: Results suggest that convenience meals providing 30 or $39 \mathrm{~g}$ protein/serving produce greater appetite control, lower postprandial glycemia and insulinemia, and reduced subsequent intake at lunch relative to a low-protein control, or no breakfast.

Trial registration: NCT01713114

Keywords: Hunger, Fullness, Appetite, Protein, Glycemic control

\footnotetext{
*Correspondence: Tia.Rains@gmail.com

'SALTT, LLC, 801 Ouilmette Ln, Wilmette, IL 60091, USA

${ }^{3}$ Biofortis Clinical Research, 211 E. Lake St, Addison, IL 60101, USA

Full list of author information is available at the end of the article
} 


\section{Background}

Protein is generally regarded to be more satiating than an equivalent amount of digestible carbohydrate or fat [1-4]. This may be particularly true when protein is consumed at breakfast versus later in the day, as studies that have fed protein at lunch or dinner have shown more variable results [5]. Acute intervention studies have shown that protein-rich breakfast meals reduce appetite and increase satiety throughout the morning relative to moderate or low-protein breakfast meals [6-8]. Protein-rich breakfast meals have also been shown to reduce energy intake at a subsequent ad libitum lunch meal [6,7,9-11]. Such effects have been demonstrated at protein intakes $\geq 20 \mathrm{~g}$, and most consistently at intakes $\geq 30 \mathrm{~g}$ of protein per meal [6,7,9-12].

The effects of a protein-rich breakfast may extend beyond the immediate postprandial period. Several investigators have reported reduced energy intakes over the 24 hour period following egg-based breakfast meals rich in protein $[7,10]$, although not all studies have produced similar results [13]. Leidy et al. [12] found that higher protein intake at breakfast (35 vs. $13 \mathrm{~g}$ ) was associated not only with greater satiety and less hunger throughout the morning, but also with reduced energy intake from snacks in the evening hours, particularly high-fat snacks.

Limited data exist regarding postprandial glucose and insulin excursions and their relationships to appetitive responses following high vs. lower protein meals. In addition to the satiety properties of dietary protein, the consumption of higher protein meals has been proposed to improve glucose homeostasis. Several meta-analyses from long-term, higher protein, weight loss and/or weight maintenance diets report reductions in glycated hemoglobin and/or fasting insulin concentrations with higher vs. normal protein diets $[14,15]$. Since larger postprandial glucose elevations have been shown to be associated with an increased risk for the development of type 2 diabetes mellitus [16] and cardiovascular disease [17], it is of interest to identify dietary strategies, such as higher protein intake at breakfast, that might improve glucose homeostasis through the reductions in these responses.

Average dietary protein intake in the US is adequate based on current recommendations [18]. However, data from the National Health and Nutrition Examination Survey (NHANES) survey suggest that the majority of dietary protein is consumed at dinner, with protein intakes at breakfast averaging $\sim 10 \mathrm{~g}$ in women and $15 \mathrm{~g}$ in men, well below levels shown to favorably affect appetite and metabolism [19]. In addition, approximately $20 \%$ of US men and women do not consume breakfast [20]. In an analysis of NHANES data, our group found that higher protein intake at breakfast was inversely associated with energy intake at lunch, and higher non-protein intake at breakfast was positively associated with energy intake at lunch [19].
Given ready-to-eat cereals and other foods requiring little preparation are frequently consumed at breakfast, convenient breakfast options high in protein would be potentially beneficial for individuals interested in reducing morning hunger and energy intake later in the day as well as glycemic excursions. The present study was undertaken to evaluate the effects of consuming two higher-protein sausage and egg-based frozen convenience breakfast meals, providing 30 or $39 \mathrm{~g}$ of protein, compared with a lower-protein, higher carbohydrate frozen convenience breakfast meal (pancakes and syrup, $3 \mathrm{~g}$ protein), and breakfast skipping, on appetite ratings, postprandial glycemic and insulinemic responses, and $a d$ libitum energy intake at a lunch meal in normal weight to overweight, premenopausal women.

\section{Methods}

\section{Design}

This was a randomized, controlled, crossover study conducted at Biofortis Clinical Research (Addison, IL) according to Good Clinical Practice Guidelines, the Declaration of Helsinki (2000), and the United States 21 Code of Federal Regulations. An institutional review board (Quorum Review IRB, Seattle, WA) approved the protocol before initiation of the study and subjects provided written informed consent before any study procedures were performed. The study included 1 screening visit and 4 test visits, each separated by at least 5 days.

\section{Participants}

Healthy premenopausal women aged 18 to $55 \mathrm{y}$, each with a body mass index (BMI) 18.5 to $29.9 \mathrm{~kg} / \mathrm{m}^{2}$ and who were regular consumers of breakfast and lunch ( $\geq 5$ days/week), were recruited to participate. Subjects were excluded if they were self-defined smokers; reported a recent weight change of $\pm 2.7 \mathrm{~kg}$; had history of surgical intervention for the treatment of obesity; used weight loss medications, supplements, programs, or meal replacement products; used medications or dietary supplements likely to markedly affect taste, smell, or appetite; or scored $>11$ on a dietary restraint scale [21]. Subjects with a history of cardiac, renal, hepatic, endocrine, pulmonary, biliary, pancreatic, gastrointestinal or neurologic disorders, or cancer (in the last 2 years); known sensitivity, allergy, or taste aversion to any of the ingredients in the study products; a history of eating disorders or alcohol abuse; and use of medications known to influence carbohydrate metabolism were also excluded from the study. Subjects who developed symptoms of active infection during the study period (e.g., upper respiratory infection) or reported antibiotic use were allowed to continue only after symptoms had been resolved and antibiotic use had been discontinued at least 5 days prior to testing. 
In total, 34 women participated in the study (Table 1). Test visits were scheduled during the follicular phase of each woman's menstrual cycle, defined as days 1 to 14 , where day 1 is the first day of menses. Participants were instructed to contact the clinic once menses began to schedule their test visits. Additional study instructions included avoidance of vigorous physical activity, consumption of alcoholic beverages, and maintenance of habitual caffeine intake within 24 hours of each test visit. Subjects were also dispensed a food record prior to their first test visit, which was copied and dispensed to each participant with instructions to replicate the same food and beverage intakes to the best of their ability after 1400 hour the day prior to subsequent test visits.

\section{Procedures}

On test days, subjects reported to the clinic ( $\sim 0800$ hour) following an overnight fast (10-12 hour). An intravenous (IV) catheter was inserted for collection of venous blood. At approximately $\mathrm{t}=-60 \mathrm{~min}$, subjects were offered $6 \mathrm{oz}$ of water, a caffeinated, non-caloric cola, caffeinated coffee, or tea with non-caloric sweetener. The beverage of their choice was replicated at subsequent test visits. At $\mathrm{t}=-12 \mathrm{~min}$, subjects were administered one of three study products with $175 \mathrm{~g}$ of water or water only, and instructed to consume approximately one-third of the study product and water every $4 \mathrm{~min}$ (Figure 1 ). Participants were instructed to consume the study product and water in their entirety. Participants were provided with $500 \mathrm{~g}$ of water and allowed to drink ad libitum throughout the remainder of the visit. Actual water intake was recorded.

Validated Visual Analog Scale (VAS) ratings [22] for appetite sensations (hunger, fullness, desire to eat, and prospective food consumption) were completed prior to study product intake $(\mathrm{t}=-25$ and $-15 \mathrm{~min})$ and at $30 \mathrm{~min}$ intervals until $240 \mathrm{~min}$. VAS ratings were recorded on a $100-\mathrm{mm}$ horizontal line anchored by "not at all" to

Table 1 Subject characteristics

\begin{tabular}{ll}
\hline Characteristic & Efficacy evaluable population \\
\hline Female & N (\%) \\
Race/Ethnicity & $34(100)$ \\
Non-Hispanic white & $20(58.8)$ \\
African American & $7(20.6)$ \\
Other & $7(20.6)$ \\
& Mean (SEM) \\
Age (y) & $32.2(1.6)$ \\
Weight (kg) & $66.9(1.5)$ \\
Body mass index (kg/m²) & $24.9(0.5)$ \\
Restraint score (Arbitrary units) & $6.5(0.6)$ \\
\hline
\end{tabular}

"extremely" in response to questions worded as "How strong is your feeling of". Palatability was assessed by a 9-point scale with the anchors "dislike extremely" and "like extremely" immediately following the last bite of study product.

Blood draws were performed at specific times (Figure 1). Seven blood samples ( $4 \mathrm{ml} / \mathrm{sample} ; 28 \mathrm{ml} /$ testing day) were collected throughout each testing day. The samples were collected in test tubes containing ethylenediaminetetraacetic acid. Within 10 min of collection, the samples were centrifuged at $-4{ }^{\circ} \mathrm{C}$ for $10 \mathrm{~min}$. The plasma was separated and stored in microcentrifuge tubes at $-80{ }^{\circ} \mathrm{C}$ for future analysis. Plasma glucose was measured through an in-house glucose oxidase assay (Thermo Fisher Scientific, USA). Plasma insulin was measured using the Milliplex MAP magnetic bead-based multi-analyte, metabolic panel (Millipore, St. Charles, MO) and Magpix Luminex technologies (Luminex Corporation, Austin, TX).

An ad libitum lunch consisting of tortellini and sauce was provided to participants following the last blood collection. Subjects were allowed $25 \mathrm{~min}$ for lunch and instructed to eat until "comfortably full". Food was weighed to the nearest gram prior to and following consumption. Subjects were provided with a standard amount of water during lunch and the quantity of water consumed was recorded. A final VAS rating was recorded following lunch at $\mathrm{t}=270 \mathrm{~min}$.

\section{Test products}

Test products included two commercially-prepared, frozen breakfast meals consisting of egg white, poultry sausage, potatoes, and cheese at two different protein levels [30 g and $39 \mathrm{~g}$ /serving; Hillshire Brands); a low protein (LP) meal consisting of mini-pancakes (Eggo ${ }^{\circ}, K^{2}$ ellogg's), syrup (Aunt Jemima ${ }^{\oplus}$, The Quaker Oats Company), butter (Land O'Lakes); and no breakfast (NB; water only) (Table 2). All test products were prepared according to manufacturer instructions. Each meal was similar in energy, total fat, and fiber contents (except water only condition), but differed in total weight (77 g, $189 \mathrm{~g}$, and $178 \mathrm{~g}$ for the LP, $30 \mathrm{~g}$ and $39 \mathrm{~g}$ bowls, respectively).

\section{Statistical analyses - VAS responses and subsequent food intake}

Statistical analyses were conducted using SAS version 9.1.3 (SAS Institute, Cary, NC). An evaluable sample size of 33 subjects was expected to provide $85 \%$ power to detect a difference of $2400 \mathrm{~mm} *$ min in the net incremental area under the curve (niAUC) for postprandial VAS scores between treatment conditions, assuming a standard deviation of $3816 \mathrm{~mm}$ * min (based on prior work by our group), for an effect size of $62 \%$. A nominal alpha of 0.017 was used for sample size calculations to account for three 


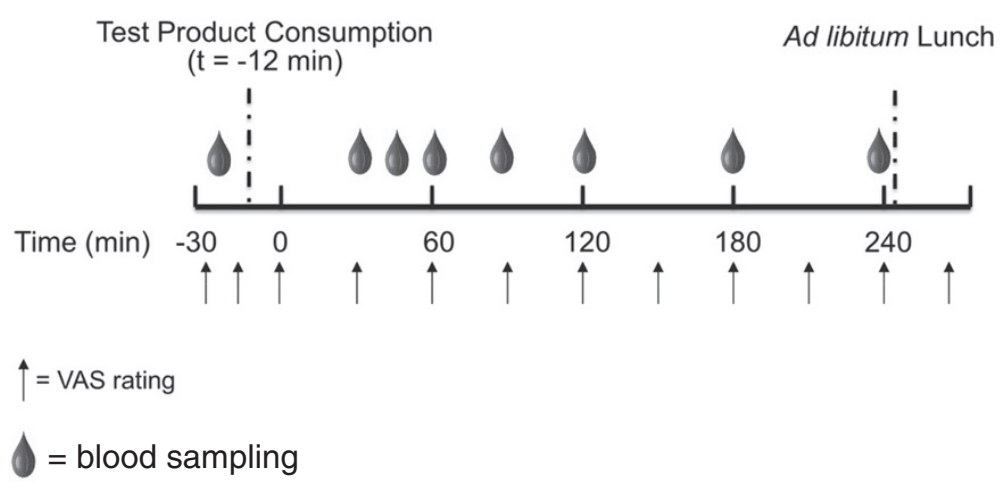

Figure 1 Test visit flow diagram.

primary comparisons between the three energy-containing meal conditions [23].

VAS rating niAUCs were calculated by applying the trapezoidal rule for both positive and negative increments from pre-meal (average of timepoints, nominal time 0 min was calculated as the average of the values at -25 and $-15 \mathrm{~min}$ ) to $240 \mathrm{~min}$, whereas total AUC was calculated for the plasma glucose and insulin concentrations throughout the $240 \mathrm{~min}$ [24]. Repeated measures analysis of variance (ANOVA) was used to assess differences between test conditions for continuous outcome variables. Initial models contained terms for treatment condition, sequence, period, age and baseline BMI, with subject included as a random effect. Models were reduced in a stepwise manner until only significant terms or treatment condition remained in the model. The Shapiro-Wilk test was used to assess normality of the distribution of residuals in the analysis models. The normality assumption was rejected for palatability, energy intake at lunch, and preload plus energy intake, therefore rank transformations were employed and the models were rerun using the transformed data. When treatment condition main effects were detected, pairwise comparisons between conditions were conducted using Tukey's adjustment for multiple comparisons. Sensitivity analyses were conducted using the overall liking palatability score as a

Table 2 Test meal characteristics ${ }^{1}$

\begin{tabular}{lllll}
\hline & NB & LP & $\mathbf{3 0 ~ g ~ P r o ~}$ & $\mathbf{3 9}$ g Pro \\
\hline Energy (kcal) & 0 & 288 & 280 & 294 \\
Protein (g) & 0 & 3 & 30 & 39 \\
Carbohydrate $(\mathrm{g})$ & 0 & 44 & 13 & 3 \\
Total fat (g) & 0 & 11 & 12 & 14 \\
Fiber (g) & 0 & 1 & 0 & 0 \\
Palatability $(\mathrm{au})^{2}$ & - & $7(7,8)$ & $7(6,8)$ & $6(4,7)$ \\
\hline
\end{tabular}

${ }^{1} \mathrm{NB}$, no breakfast; LP, low protein; Pro, protein.

${ }^{2}$ Palatability was assessed by a 9-point scale with $1=$ "dislike extremely" and $9=$ "like extremely." Median values (interquartile limits) are presented. covariate in models for appetite ratings and energy intake at lunch with the no breakfast condition excluded.

For the appetite and food intake outcomes, the primary efficacy analysis was completed on an efficacy evaluable (EE) sample that included all subjects who consumed the $39 \mathrm{~g}$ protein breakfast and at least one other condition. A secondary analysis was completed on a per protocol (PP) sample, a subset of the EE population excluding those subjects who had significant protocol deviations (e.g., use of an excluded medication, illness that caused rescheduling of visits) during the treatment period. Subjects in the PP population completed all test visits. All decisions were made prior to breaking the treatment code or locking the database by people unaware of the order of treatments. Results were similar for the EE and PP analyses; therefore, outcomes are presented only for the EE sample. However, for the glucose and insulin measures, only those completing all test conditions were included and thus a PP analysis was performed.

\section{Results}

\section{Palatability}

Ratings for appearance, texture, flavor, and overall liking were higher (more palatable) for the LP and $30 \mathrm{~g}$ protein conditions versus the $39 \mathrm{~g}$ protein conditions $(p<0.02$ for all). There were no differences between the $30 \mathrm{~g}$ and LP conditions. Despite the fact that there were differences, there were no statistically significant associations between overall liking and any of the appetitive ratings or energy intake at lunch. Similarly, when palatability rating was included as a covariate in a subset analysis that excluded the no breakfast condition, palatability rating was did not significantly reduce the unexplained variance.

\section{Appetite sensation ratings}

Results for hunger, fullness, desire to eat, and prospective food consumption are depicted in the line graphs 
(individual timepoints) and bar graphs (niAUC) in Figures 2 and 3. For each appetite response, there was a main effect of treatment condition $(p<0.001)$. Pairwise comparisons showed that both the $30 \mathrm{~g}$ and $39 \mathrm{~g}$ protein conditions led to greater appetite control and satiety based on the niAUC values $(p<0.001$ for all) compared to the NB and LP breakfast. The LP condition also produced greater ratings for satiety and reduced hunger relative to the no breakfast condition $(p<0.01$ for all). There were no differences between the 30 and $39 \mathrm{~g}$ conditions for any appetite sensation rating. An exploratory analysis was conducted to compare treatment conditions for appetite sensation ratings at the $240 \mathrm{~min}$ timepoint immediately prior to the lunch meal. Results are summarized in Table 3. All treatments except the $30 \mathrm{~g}$ and $39 \mathrm{~g}$ protein conditions differed significantly for ratings of hunger, fullness and desire to eat $(\mathrm{p}<0.05)$, with the $30 \mathrm{~g}$ and $39 \mathrm{~g}$ protein conditions producing the lowest ratings for hunger and desire to eat and the highest ratings for fullness. Prospective food consumption ratings did not differ significantly between the LP and 30 g protein conditions $(\mathrm{p}=0.075)$, as well as between the $30 \mathrm{~g}$ and $39 \mathrm{~g}$ protein conditions ( $\mathrm{p}=0.587$ ), but each of these conditions produced significantly lower ratings compared to NB (all $\mathrm{p}<0.05$ ).

\section{Metabolic responses}

Results for plasma glucose and insulin are depicted in the line graphs (individual timepoints) and bar graphs
(AUC) in Figure 4. No main effect of treatment condition was detected for the glucose AUC response. However, a main effect of treatment condition was detected for glucose peak $(p<0.001)$ and the postprandial change in glucose $(p<0.001)$. Pairwise comparisons showed that both the NB and the $39 \mathrm{~g}$ protein conditions led to a lower glucose peak (both, $96 \pm 1 \mathrm{mg} / \mathrm{dL} ; p<0.05$ for both) compared to the LP $(112 \pm 3 \mathrm{mg} / \mathrm{dL})$ and the $30 \mathrm{~g}$ protein $(101 \pm 2 \mathrm{mg} / \mathrm{dl})$ conditions, while the $30 \mathrm{~g}$ protein condition led to a lower glucose peak $(p<0.001)$ compared to the LP condition. Additionally, pairwise comparisons showed that both the NB and the $39 \mathrm{~g}$ protein condition led to a smaller postprandial glucose change from pre-breakfast $(-14 \pm 1 \mathrm{mg} / \mathrm{dL}$ and $-16 \pm$ $1 \mathrm{mg} / \mathrm{dL}$, respectively; $p<0.001$ for both) compared to the $\mathrm{LP}(-41 \pm 2 \mathrm{mg} / \mathrm{dL})$ and the $30 \mathrm{~g}$ protein condition $(-23 \pm 2 \mathrm{mg} / \mathrm{dL})$, while the $30 \mathrm{~g}$ protein condition led to a smaller postprandial glucose change $(p<0.001)$ vs. the LP condition. Lastly, the $39 \mathrm{~g}$ protein condition led to a smaller postprandial change in glucose $(p<0.05)$ compared to the NB condition.

Main effects of treatment condition were detected for the insulin AUC response, peak insulin, and postprandial changes $(p<0.001$ for all). Pairwise comparisons showed that the NB condition led to lower insulin AUC $(p<0.001$ for all) compared to all other breakfast conditions. The $30 \mathrm{~g}$ and $39 \mathrm{~g}$ protein conditions led to lower insulin AUC ( $p<0.05$ for both) vs. the LP breakfast with no differences between the $30 \mathrm{~g}$ and $39 \mathrm{~g}$ protein conditions. The NB
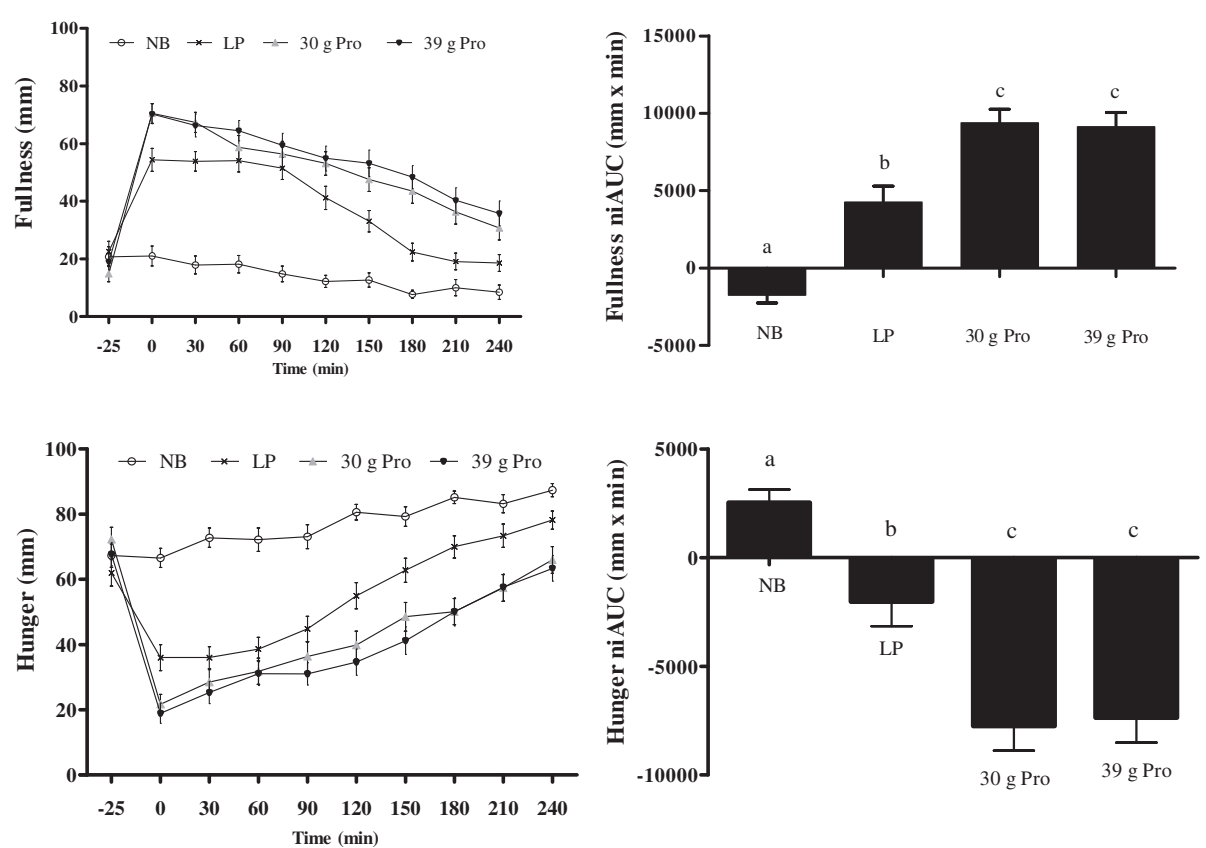

Figure 2 Appetite VAS ratings (hunger and fullness) at each timepoint and niAUC values for each condition. Data are presented as mean \pm SEM. Different letters indicate differences between conditions $(p<0.0001)$. Pairwise comparisons between conditions were conducted using Tukey's adjustment for multiple comparisons. 

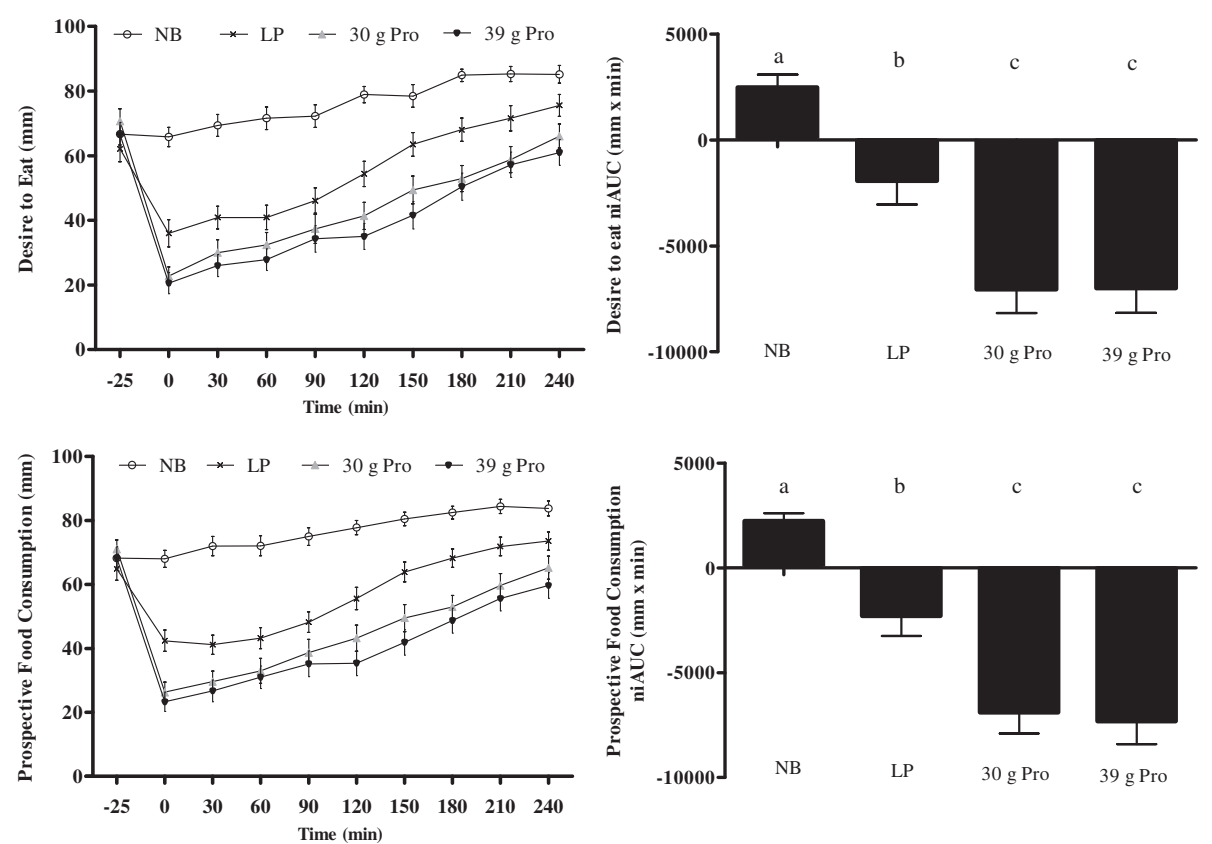

Figure 3 Appetite VAS ratings at each timepoint (left) and niAUC values (right) for each condition. Data are for desire to eat and prospective food consumption. Data are presented as mean \pm SEM. Different letters indicate differences between conditions $(p<0.0001)$. Pairwise comparisons between conditions were conducted using Tukey's adjustment for multiple comparisons.

condition led to a lower insulin peak $(7 \pm 1 \mathrm{pg} / \mathrm{mL} ; p<0.001$ for all) compared to all breakfast conditions (i.e., lowprotein (pancakes): $37 \pm 3 \mathrm{pg} / \mathrm{ml} ; 30 \mathrm{~g}$ protein: $20 \pm$ $2 \mathrm{pg} / \mathrm{mL}$; and $39 \mathrm{~g}$ protein: $16 \pm 2 \mathrm{pg} / \mathrm{mL})$. The $39 \mathrm{~g}$ protein condition led to a lower insulin peak $(p<0.05$ for both) compared to the LP and the $30 \mathrm{~g}$ protein conditions. The $30 \mathrm{~g}$ protein condition led to a lower insulin peak $(p<0.001)$ vs. LP condition. Lastly, the NB condition led to the smallest postprandial change from pre-breakfast in insulin $(-4 \pm 1 \mathrm{pg} / \mathrm{mL} ; p<0.001$ for all $)$ compared to all breakfast meals (i.e. LP: $-34 \pm 3 \mathrm{pg} / \mathrm{ml}$; $30 \mathrm{~g}$ protein: $-17 \pm 2 \mathrm{pg} / \mathrm{mL}$; and $39 \mathrm{~g}$ protein: $-11 \pm$ $2 \mathrm{pg} / \mathrm{mL}$. The $39 \mathrm{~g}$ protein condition led to a smaller postprandial change in insulin ( $p<0.01$ for both) compared to the LP and the $30 \mathrm{~g}$ protein conditions. The $30 \mathrm{~g}$ protein condition led to a smaller postprandial change in insulin $(p<0.001)$ vs. the LP condition.

\section{Lunch energy intake}

Median energy intake at the lunch meal was reduced by approximately $15 \%$ following the $30 \mathrm{~g}$ and $39 \mathrm{~g}$ protein conditions versus the NB condition ( $p \leq 0.03$; Figure 5). Compared to the LP breakfast, energy intake was lower following the $39 \mathrm{~g}$ protein condition $(p<0.001)$, and was lower with the $30 \mathrm{~g}$ protein breakfast, but this result was only marginally statistically significant $(p=0.053)$. There was no significant difference in energy intake between the LP condition and NB condition. Median total energy intake from the test condition + lunch meal was higher for all meals versus the no breakfast condition $(p<0.001)$. Compared to the LP meal, total energy intake was lower after the $39 \mathrm{~g}$ protein meal $(p<0.01)$. There were no differences between the 30 and $39 \mathrm{~g}$ conditions for energy intake at lunch or preload + energy intake at lunch.

Table 3 Appetite sensation ratings at 240 min by breakfast meal condition ${ }^{1}$

\begin{tabular}{llllll}
\hline & NB & LP & 30 g Pro & 39 g Pro & p-value \\
& Median (interquartile limits) & & & \\
\hline Hunger (mm) & $91(79,96)^{a}$ & $81(70,91)^{b}$ & $71(50,84)^{c}$ & $69(49,80)^{c}$ & $<0.0001$ \\
Fullness (mm) & $3(1,12)^{\mathrm{a}}$ & $15(9,24)^{\mathrm{b}}$ & $26(10,54)^{c}$ & $33(14,59)^{c}$ & $<0.0001$ \\
Desire to eat (mm) & $89(81,95)^{\mathrm{a}}$ & $76(69,92)^{\mathrm{b}}$ & $69(47,83)^{c}$ & $69(39,80)^{c}$ & $<0.0001$ \\
Prospective food consumption (mm) & $85(77,93)^{\mathrm{a}}$ & $77(64,84)^{\mathrm{b}}$ & $67(50,82)^{\mathrm{b}, \mathrm{c}}$ & $69(40,79)^{\mathrm{c}}$ & $<0.0001$ \\
\hline
\end{tabular}

${ }^{1} \mathrm{NB}$, no breakfast; LP, low protein; Pro, protein.

$a, b, c$ Different superscripted letters denote statistically significant differences $(p<0.05)$. 

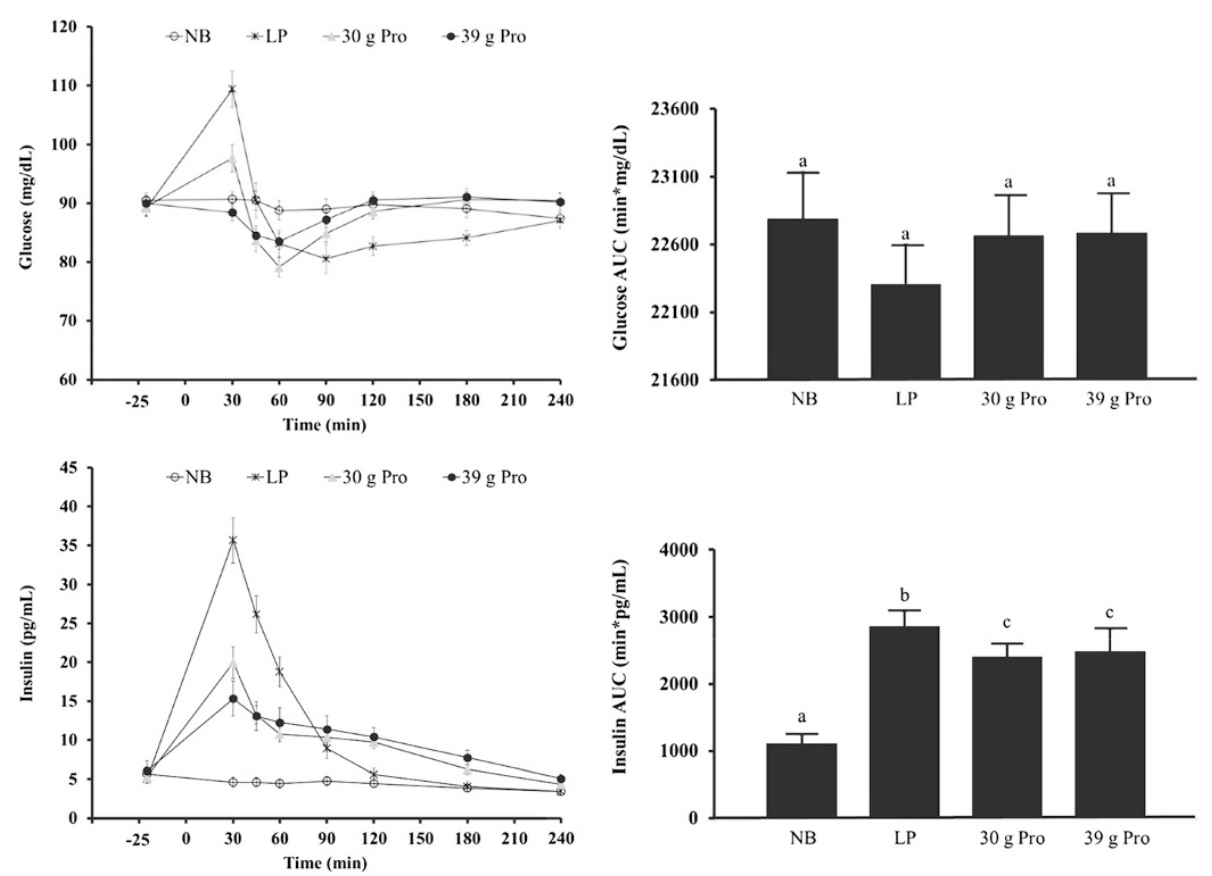

Figure 4 Plasma glucose and insulin at each timepoint (left) and AUC values (right) for each condition. Data are presented as mean \pm SEM. Different letters indicate differences between conditions $(p<0.0001)$. Pairwise comparisons between conditions were conducted using Tukey's adjustment for multiple comparisons.

\section{Discussion}

The results of this study showed that consumption of protein-rich convenience breakfast meals led to reductions in perceived hunger, increased satiety, and reductions in postprandial glucose and insulin excursions compared to a low-protein meal in normal to overweight, premenopausal women. The protein-rich breakfast meals also resulted in reduced energy intake at the ad libitum lunch meal, although results only reached significance for the $39 \mathrm{~g}$ protein meal. Thus, consumption of a high protein, sausage and egg-based, ready-to-heat meal may be an option for facilitating satiety throughout the morning, reducing postprandial glycemic and insulinemic excursions, and moderating energy intake at lunch.
The satiety and food intake findings are similar to results reported by other investigators in acute intervention trials using breakfasts based on solid food sources of protein. Eggs and meat as sources of protein, in particular, have been associated with greater perceived satiety and/or improved glycemic control in several studies $[1,6,7,10,12,25,26]$. For example, Ratliff et al. [10] compared the effects of an egg-based breakfast to a bagel-based breakfast in a group of healthy men. Similar to the results of the present study, perceived hunger, glucose, insulin, and energy intake at the lunch meal were all reduced following the higher protein breakfast. However, to the best of our knowledge, very few prior studies have evaluated the appetitive effects of protein-based, frozen convenience

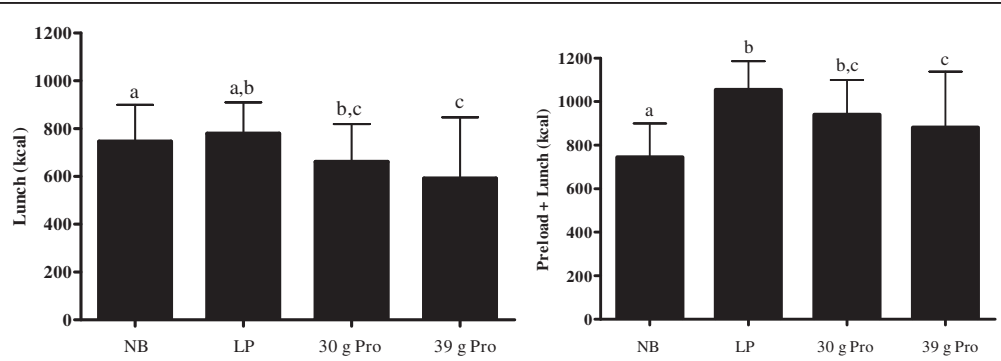

Figure 5 Lunch (left) and total (preload + lunch; right) energy intake following each condition $(\mathbf{t}=\mathbf{2 4 0} \mathbf{m i n})$. Data are presented as median (75th percentile). Different letters indicate differences between conditions ( $p<0.05$, note - energy intake at lunch for the $30 \mathrm{~g}$ Pro breakfast vs. LP breakfast $p=0.053$ ). Pairwise comparisons between conditions were conducted using Tukey's adjustment for multiple comparisons. 
meals. Such meals serve as an easy to prepare option, compared to other high-protein foods traditionally consumed at breakfast in the U.S. (e.g., fresh breakfast meats, fresh eggs), which require a greater degree of preparation. This is further supported by data indicating that a primary barrier associated with breakfast is the lack of availability and convenience [27].

The present work included two levels of protein served as part of a commonly consumed breakfast meal. There were minimal differences in responses between the proteincontaining meals, suggesting that both protein levels were sufficient to elicit a greater satiety response and to reduce postprandial glycemic and insulinemic excursions compared with the low-protein meal. The differences in glucose and insulin responses elicited by the test meals were expected because a substitution of protein for carbohydrate was employed, thus reducing the available carbohydrate load. Nevertheless, chronic reduction of dietary carbohydrate has been demonstrated to produce notable metabolic effects, including lowering the circulating concentration of triglycerides, reducing blood pressure, and lessening the demand for insulin production by the pancreatic beta-cells [28]. Moreover, ingestion of protein at a meal tends to increase insulin secretion without significantly increasing the plasma glucose concentration (compared to water ingestion) in the postprandial period [29]. Lastly, elevations in plasma insulin and glucose have been shown to reduce appetitive sensations [30,31]. Thus, it is notable that the appetitive effects observed with higher protein and lower carbohydrate were present despite lower insulin and glucose concentrations.

Other investigations utilizing beverages or semi-liquid applications (e.g., yogurt or custard) to evaluate the satiating properties of protein have shown similar effects to those observed in the present study [32-36]. However, such vehicles are not among the top breakfast choices in the U.S. [27]. Further, the present work included overweight and normal weight women, a group more likely to engage in strategies to reduce body weight than their male counterparts [37]. Results from several long-term intervention trials have provided evidence that higher protein, reduced carbohydrate diets may help to enhance weight loss and/or maintain lean body mass during weight loss [14,15,38-40]. Increased satiation, and therefore better adherence to caloric restriction, is one potential mechanism by which high protein diets may facilitate weight loss. High protein, easy to prepare breakfast options with greater satiating potential would likely facilitate the consumption of calorically-restricted, protein-rich diets.

The mechanisms whereby dietary protein promotes satiety are not completely understood. It has been hypothesized that a high-protein meal may modulate the post-absorptive release of hormones and neurochemicals in the gastrointestinal tract that down-regulate appetite [41]. In particular, consumption of high-protein meals has been shown to decrease levels of the hungerstimulating hormone ghrelin and/or promote the increase in the satiety-stimulating hormones peptide YY (PYY) and glucagon-like peptide-1 (GLP-1), resulting in increased perceptions of satiety $[8,9,26,42,43]$. Unfortunately, data for ghrelin, PYY, and GLP-1 for the present study are not available. A majority of studies that have assessed the relationship between postprandial insulin levels and appetite sensations have suggested that insulin has an acute effect to suppress appetite $[30,44]$, although conflicting results have been reported $[45,46]$. Intracerebroventricular or systemic injections of insulin suppress food intake in a dosedependent manner in animal models, suggesting a direct involvement in satiety [47]. It is therefore notable that appetite ratings were reduced with the high protein conditions compared to the low protein (higher carbohydrate) breakfast, despite lower insulin (and glucose) responses. Some investigators have suggested that increased thermogenesis following consumption of high-protein meals, as well as changes in substrate oxidation may influence appetitive signals that affect food intake [48,49]. Additional studies will be needed to more fully define the mechanisms responsible for the effects of substituting protein for carbohydrate observed in the present study. It is also suggested that additional research is needed to assess the substitution of protein for dietary fat. Future research of interest would also include studies in which protein is substituted for fat, since the current study cannot separate the effects of increasing the protein content of the study breakfast meals from those of reducing the carbohydrate content.

Both buffet lunch and uniform food models, such as the tortellini and sauce lunch used in the present study, have been used extensively in appetite research [50]. A uniform food model was used in the present investigation because the main objective was related to energy intake rather than food selection. Thus, a limitation of the study is that possible differences in food or macronutrient preferences at lunch could not be assessed.

Another limitation is the short-term nature of the measurement period. It is possible that appetitive sensations or energy intake would increase later in the day to compensate, or even overcompensate, for reductions in energy intake observed at the lunch meal. However, results from Leidy et al. [12] suggest that this may not be the case, as total daily energy intake was reduced when a high-protein breakfast was consumed, compared with a lower protein breakfast meal. Notably, in that trial, a 7-day period of acclimation was employed for both breakfast conditions, suggesting that the effects of higher protein breakfasts on appetite do not dissipate, at least after several days of consumption.

The possibility cannot be ruled out that expectations surrounding each breakfast condition and differences in 
the sensory characteristics influenced the results. The present trial evaluated commercially-available breakfast options, therefore matching the sensory properties of the test conditions was not possible. However, all products were considered to be relatively well-liked and there were only measurable differences in the palatability of the highest protein condition relative to the low protein and $30 \mathrm{~g}$ protein conditions. Inclusion of the overall palatability rating as a covariate in sensitivity analyses for appetite ratings and energy intake at lunch did not significantly reduce the unexplained variance, suggesting that differences in palatability were unlikely to have materially influenced the results.

Differences in the physical characteristics of the study products may have also influenced orogastric transit time. In an effort to control this to the degree possible, subjects were instructed to eat a portion of each condition at specific intervals over a 12-minute period (approximately one-third during each of three 4-min periods). However, we cannot rule out the possibility that differences in consumption patterns (e.g., chewing) or orogastric transit time influenced our findings. Further, the weight and volume of the products differed. Such characteristics have been previously shown to affect perceived satiety, however our objective was to evaluate conventional breakfast options at an equivalent caloric level, and as such, differences in weight and volume were unavoidable due to the nature of the breakfast meals [51].

\section{Conclusion}

In conclusion, the results of the present investigation suggest that sausage/egg convenience meals providing $30 \mathrm{~g}$ or $39 \mathrm{~g}$ protein per serving produce greater appetite control, reduce postprandial glycemic and insulinemic responses, and lower energy intake at lunch relative to a lower-protein, higher carbohydrate, breakfast meal.

\section{Competing interests}

$\mathrm{TR}, \mathrm{HL}, \mathrm{KM}, \mathrm{KS}$, and $\mathrm{AL}$ received research funding from Hillshire Brands.

\section{Authors' contributions}

$\mathrm{TR}, \mathrm{HL}$, and $\mathrm{KM}$ conceived the study concept and design and analyzed/ interpreted the data. Additionally, TR, HL, and KM drafted and revised the manuscript for important intellectual content. $\mathrm{AL}, \mathrm{KS}$, and $\mathrm{KM}$ participated in study supervision. All authors read and approved the final manuscript.

\section{Acknowledgements}

The authors thank the study participants for their dedication and compliance during the testing days. This trial was funded by Hillshire Brands, Chicago, IL. Financial supporters had no role in the design, implementation, analysis or interpretation of data or preparation of the manuscript.

\section{Author details}

${ }^{1}$ SALTT, LLC, 801 Ouilmette Ln, Wilmette, IL 60091, USA. ²Department of Nutrition and Exercise Physiology, University of Missouri, 307 Gwynn Hall, Columbia, MO 65201, USA. ${ }^{3}$ Biofortis Clinical Research, 211 E. Lake St, Addison, IL 60101, USA. ${ }^{4}$ Midwest Center for Metabolic \& Cardiovascular Research, 489 Taft Ave., Suite 202, Glen Ellyn, IL 60137, USA.
Received: 29 August 2014 Accepted: 20 January 2015

Published online: 10 February 2015

\section{References}

1. Holt SH, Miller JC, Petocz P, Farmakalidis E. A satiety index of common foods. Eur J Clin Nutr. 1995;49:675-90.

2. Stubbs J, Ferres S, Horgan G. Energy density of foods: effects on energy intake. Crit Rev Food Sci Nutr. 2000:40:481-515.

3. Porrini M, Santangelo A, Crovetti R, Riso P, Testolin G, Blundell JE. Weight, protein, fat, and timing of preloads affect food intake. Physiol Behav. 1997;62:563-70.

4. Johnstone AM, Stubbs RJ, Harbron CG. Effect of overfeeding macronutrients on day-to-day food intake in man. Eur J Clin Nutr. 1996;50:418-30.

5. Leidy HJ, Bossingham MJ, Mattes RD, Campbell WW. Increased dietary protein consumed at breakfast leads to an initial and sustained feeling of fullness during energy restriction compared to other meal times. Br J Nutr. 2009;101:798-803.

6. Fallaize R, Wilson L, Gray J, Morgan LM, Griffin BA. Variation in the effects of three different breakfast meals on subjective satiety and subsequent intake of energy at lunch and evening meal. Eur J Nutr. 2013;52:1353-9.

7. Vander Wal JS, Marth JM, Khosla P, Jen KL, Dhurandhar NV. Short-term effect of eggs on satiety in overweight and obese subjects. J Am Coll Nutr. 2005;24:510-5.

8. Leidy HJ, Carnell NS, Mattes RD, Campbell WW. Higher protein intake preserves lean mass and satiety with weight loss in pre-obese and obese women. Obesity. 2007;15:421-9.

9. Leidy HJ, Racki EM. The addition of a protein-rich breakfast and its effects on acute appetite control and food intake in 'breakfast-skipping' adolescents. Int J Obes (Lond). 2010;34:1125-33.

10. Ratliff J, Leite JO, de Ogburn R, Puglisi MJ, VanHeest J, Fernandez ML. Consuming eggs for breakfast influences plasma glucose and ghrelin, while reducing energy intake during the next 24 hours in adult men. Nutr Res. 2010;30:96-103.

11. Clegg M, Shafat A. Energy and macronutrient composition of breakfast affect gastric emptying of lunch and subsequent food intake, satiety and satiation. Appetite. 2010;54:517-23.

12. Leidy HJ, Ortinau LC, Douglas SM, Hoertel HA. Beneficial effects of a higher-protein breakfast on the appetitive, hormonal, and neural signals controlling energy intake regulation in overweight/obese, "breakfast-skipping", late-adolescent girls. Am J Clin Nutr. 2013;97:677-88.

13. Alfenas Rde C, Bressan J, Paiva AC. Effects of protein quality on appetite and energy metabolism in normal weight subjects. Arq Bras Endocrinol Metabol. 2010;54:45-51.

14. Dong JY, Zhang ZL, Wang PY, Qin LQ. Effects of high-protein diets on body weight, glycaemic control, blood lipids and blood pressure in type 2 diabetes: meta-analysis of randomised controlled trials. Br J Nutr. 2013;110:781-9.

15. Clifton PM, Condo D, Keogh JB. Long term weight maintenance after advice to consume low carbohydrate, higher protein diets-a systematic review and meta analysis. Nutr Metab Cardiovasc Dis. 2014;24:224-35.

16. Lorenzo C, Okoloise M, Williams K, Stern MP, Haffner SM. The metabolic syndrome as predictor of type 2 diabetes: the San Antonio heart study. Diabetes Care. 2003;26:3153.

17. Brunner EJ, Shipley MJ, Witte DR, Fuller JH, Marmot MG. Relation between blood glucose and coronary mortality over 33 years in the Whitehall Study. Diabetes Care. 2006;29:26-31.

18. Fulgoni 3rd VL. Current protein intake in America: analysis of the National Health and Nutrition Examination Survey, 2003-2004. Am J Clin Nutr. 2008:87:1554S-7

19. Rains TM, Maki KC, Fulgoni 3rd VL, Auestad N. Protein intake at breakfast is associated with reduced energy intake at lunch: an analysis of NHANES 2003-2006. FASEB J. 2013;27:349.7.

20. Kant AK, Graubard BI. Secular trends in patterns of self-reported food consumption of adult Americans: NHANES 1971-1975 to NHANES 1999-2002. Am J Clin Nutr. 2006:84:1215-23.

21. Stunkard AJ, Messick $S$. The three-factor eating questionnaire to measure dietary restraint, disinhibition and hunger. J Psychosom Res. 1985;29:71-83.

22. Flint A, Raben A, Blundell JE, Astrup A. Reproducibility, power and validity of visual analogue scales in assessment of appetite sensations in single test meal studies. Int J Obes Relat Metab Disord. 2000;24:38-48.

23. Šidák Z. On probabilities of rectangles in multivariate normal Student distributions: their dependence on correlations. Ann Math Statist. 1971;41:169-75. 
24. Brouns F, Bjorck I, Frayn KN, Gibbs AL, Lang V, Slama G, et al. Glycaemic index methodology. Nutr Res Rev. 2005;18:145-71.

25. Meinert L, Kehlet U, Aaslyng MD. Consuming pork proteins at breakfast reduces the feeling of hunger before lunch. Appetite. 2012;59:201-3.

26. Belza A, Ritz C, Sorensen MQ, Holst JJ, Rehfeld JF, Astrup A. Contribution of gastroenteropancreatic appetite hormones to protein-induced satiety. Am J Clin Nutr. 2013;97:980-9.

27. International Food Information Council, IFIC. (2008, December 19). IFIC Review: Breakfast and Health. Retreived from http://www.foodinsight.org/ Content/6/FIC\%20Brkfast\%20Review\%20FINAL.pdf. Accessed November 6, 2012.

28. Sacks FM, Carey VJ, Anderson CAM, Miller III ER, Copeland T, Charleston J, et al. Effects of high vs low glycemic index of dietary carbohydrate on cardiovascular disease risk factors and insulin sensitivity. JAMA. 2014;312:2531-41.

29. Gannon MC, Nuttall JA, Damberg G, Gupta V, Nuttall FG. Effect of protein ingestion on the glucose appearance rate in people with type 2 diabetes. J Clin Endocrinol Metab. 2001;86:1040-7.

30. Anderson HG, Catherine NLA, Woodend DM, Wolever TMS. Inverse association between the effect of carbohydrates on blood glucose and subsequent short-term food intake in young men. Am J Clin Nutr. 2002;76:1023-30.

31. Karatsoreos IN, Thaler JP, Borgland SL, Champagne FA, Hurd YL, Hill MN. Food for thought: hormonal, experiential, and neural influences on feeding and obesity. J Neurosci. 2013;33:17610-6.

32. Probst A, Humpeler S, Heinzl H, Blasche G, Ekmekcioglu C. Short-term effect of macronutrient composition and glycemic index of a yoghurt breakfast on satiety and mood in healthy young men. Forsch Komplementmed. 2012;19:247-51.

33. Bertenshaw EJ, Lluch A, Yeomans MR. Satiating effects of protein but not carbohydrate consumed in a between-meal beverage context. Physiol Behav. 2008;93:427-36.

34. Dove ER, Hodgson JM, Puddey IB, Beilin L, Lee YP, Mori TA. Skim milk compared with a fruit drink acutely reduces appetite and energy intake in overweight men and women. Am J Clin Nutr. 2009;90:70-5.

35. Hursel $R$, van der Zee $L$, Westerterp-Plantenga MS. Effects of a breakfast yoghurt, with additional total whey protein or caseinomacropeptide-depleted alpha-lactalbumin-enriched whey protein, on diet-induced thermogenesis and appetite suppression. Br J Nutr. 2010;103:775-80.

36. Tsuchiya A, Almiron-Roig E, Lluch A, Guyonnet D, Drewnowski A. Higher satiety ratings following yogurt consumption relative to fruit drink or dairy fruit drink. J Am Diet Assoc. 2006;106:550-7.

37. Bish CL, Blanck HM, Serdula MK, Marcus M, Kohl 3rd HW, Khan LK. Diet and physical activity behaviors among Americans trying to lose weight: 2000 behavioral risk factor surveillance system. Obesity Res. 2005;13:596-607.

38. Maki KC, Rains TM, Kaden VN, Raneri KR, Davidson MH. Effects of a reduced-glycemic-load diet on body weight, body composition, and cardiovascular disease risk markers in overweight and obese adults. Am J Clin Nutr. 2007:85:724-34.

39. Vander Wal JS, Gupta A, Khosla P, Dhurhandar NV. Egg breakfast enhances weight loss. Int J Obes (Lond). 2008:32:1545-51.

40. Weigle DS, Breen PA, Matthys CC, Callahan HS, Meeuws KE, Burden VR, et al. A high-protein diet induces sustained reductions in appetite, ad libitum caloric intake, and body weight despite compensatory changes in diurnal plasma leptin and ghrelin concentrations. Am J Clin Nutr. 2005;82:41-8.

41. Bowen J, Noakes M, Trenerry C, Clifton PM. Energy intake, ghrelin, and cholecystokinin after different carbohydrate and protein preloads in overweight men. J Clin Endocrinol Metab. 2006;91:1477-83.

42. Batterham RL, Heffron H, Kapoor S, Chivers JE, Chandarana K, Herzog H, et al. Critical role for peptide $Y$ in protein-mediated satiation and body-weight regulation. Cell Metab. 2006:4:223-33.

43. Blom WA, Lluch A, Stafleu A, Vinoy S, Holst JJ, Schaafsma G, et al. Effect of a high-protein breakfast on the postprandial ghrelin response. Am J Clin Nutr. 2006;83:211-20.

44. Schloegl H, Percik R, Horstmann A, Villringer A, Stumvoll M. Peptide hormones regulating appetite-focus on neuroimaging studies in humans. Diabetes Metab Res Rev. 2011;27:104-12.

45. Holt SH, Miller JB. Increased insulin responses to ingested foods are associated with lessened satiety. Appetite. 1995;24:43-54.

46. Leidy HJ, Apolzan JW, Mattes RD, Campbell WW. Food form and portion size affect postprandial appetite sensations and hormonal responses in healthy, nonobese, older adults. Obesity. 2010;18:293-9.
47. Sobrino Crespo C, Perianes Cachero A, Puebla Jimenez L, Barrios V, Arilla Ferreiro E. Peptides and food intake. Front Endocrinol. 2014;5:58.

48. Crovetti R, Porrini M, Santangelo A, Testolin G. The influence of thermic effect of food on satiety. Eur J Clin Nutr. 1998;52:482-8.

49. Veldhorst M, Smeets A, Soenen S, Hochstenbach-Waelen A, Hursel R, Diepvens K, et al. Protein-induced satiety: effects and mechanisms of different proteins. Physiol Behav. 2008;94:300-7.

50. Blundell J, de Graaf C, Hulshof T, Jebb S, Livingstone B, Lluch A, et al. Appetite control: methodological aspects of the evaluation of foods. Obes Rev. 2010;11:251-70.

51. Williams RA, Roe LS, Rolls BJ. Assessment of satiety depends on the energy density and portion size of the test meal. Obesity. 2014;22:318-24

\section{Submit your next manuscript to BioMed Central and take full advantage of:}

- Convenient online submission

- Thorough peer review

- No space constraints or color figure charges

- Immediate publication on acceptance

- Inclusion in PubMed, CAS, Scopus and Google Scholar

- Research which is freely available for redistribution

Submit your manuscript at www.biomedcentral.com/submit 